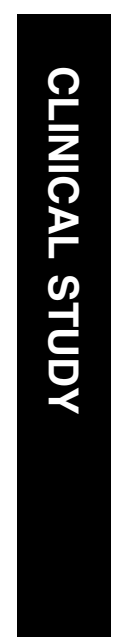

\section{The effect on visual function of Hydroview intraocular lens opacification: a cross-sectional study}

${ }^{1}$ Department of Clinical Sciences at South Bristol, Academic Unit of Ophthalmology, University of Bristol, Bristol, UK

${ }^{2}$ Department of Ophthalmology, University Hospitals Bristol NHS Foundation Trust, Bristol, UK

${ }^{3}$ Department of Clinical Sciences at South Bristol, Institute of Child life and Health, University of Bristol, Bristol, UK

Correspondence:

MSJ Blundell,

Academic Unit of

Ophthalmology,

University of Bristol,

Department of Clinical

Sciences at South Bristol,

University of Bristol, Bristol,

Avon BS1 2LX, UK

Tel: + 4407966497644 ;

Fax: + 4401179284721 .

E-mail: msjb1@doctors.org. uk

Received: 15 November 2009

Accepted in revised form: 15 April 2010

Published online: 11 June 2010

Previously presented at the association of research in vision and ophthalmology (ARVO) general meeting on the 5th May 2009

\begin{abstract}
Purpose Hydroview intraocular lenses (IOLs) have been associated with symptomatic opacification of the optic necessitating IOL exchange. Glare and misty vision have been noted as common presenting symptoms. This study's purpose was to investigate the impact of IOL opacification on objective measurements of visual function, including glare, and on vision-related quality of life. Methods All patients who underwent Hydroview IOL implantation at Bristol Eye Hospital between December 2000 and the end of February 2001 were invited for assessment along with patients found to have Hydroview IOL opacification in routine ophthalmic clinics. Glare, visual acuity, contrast sensitivity, visual field, and colour vision were assessed. Vision-related quality of life and subject's symptoms were determined by questionnaire. IOL opacification was assessed by slit lamp bio-microscopy and anterior segment photography.

Results Data from 129 patients were analysed. Fifty subjects had opacified IOLs and 79 clear IOLs. Subjects with opacified IOLs showed dramatically higher levels of glare (adjusted mean difference of $0.63 \mathrm{log}$ units $95 \% \mathrm{CI}, 0.45-0.82 ; P<0.001)$ with only mildly reduced visual acuity (adjusted mean difference of $0.09 \log$ MAR units $95 \% \mathrm{CI}$, $0.03-0.15 ; P=0.002$ ). Opacification was associated with poorer contrast sensitivity $(P<0.001)$, visual field $(P<0.001)$, and with lower vision-related quality of life $(P<0.001)$. Conclusions This study highlights the significant impact IOL opacification has on visual performance and experience, in particular glare and consequent impact on quality of life. The study shows that to
\end{abstract}

MSJ Blundell', EJ Mayer ${ }^{2}$, NE Knox Cartwright ${ }^{2}$, LP Hunt ${ }^{3}$, DM Tole ${ }^{2}$ and AD Dick ${ }^{1}$ quantify accurately the effect of IOL opacification on vision glare must be assessed. Eye (2010) 24, 1590-1598; doi:10.1038/eye.2010.90; published online 11 June 2010

Keywords: intraocular lens; cataract; postoperative complication; opacification

\section{Introduction}

In developed countries, cataract surgery is often the most frequently performed operation ${ }^{1}$ and greatest single expense to healthcare systems. ${ }^{2}$ As a result, any complication of this procedure has significant public health, clinical governance, and resource management implications. Opacification of the optic of implanted intraocular lenses (IOLs) is a rare, but important postoperative complication that can affect visual function to the point that IOL exchange is required..$^{3-6}$ Optic opacification can be either a primary or secondary phenomenon, the former being because of a problem with the IOL itself and the latter a consequence of the intraocular environment, for example uveitis. ${ }^{7}$

Although any IOL can be affected by secondary opacification, primary opacification appears more common in hydrophilic acrylic IOLs, having been associated with the Aquasense (Ophthalmic Innovation International, Ontario, Canada), ${ }^{8}$ MemoryLens (Ciba Vision, Duluth, GA, USA), ${ }^{9-11}$ SC60B-OUV (Medical Development Research, Clearwater, FL, USA), ${ }^{12-15}$ and the Hydroview H60M IOL (Bausch and Lomb, Rochester, New York, NY, USA). ${ }^{3,6,7,76-19}$

Between 1997 and 2001, 88527 Hydroview lenses were supplied to UK hospitals, ${ }^{6}$ and worldwide it is estimated that $>400000$ of these lenses have been implanted. ${ }^{20}$ Incidence of 
opacification has been estimated at between 4 and $15.4 \% .^{3,21}$ In 2004, an MHRA report stated that peak incidence occurred between 12 and 36 months postimplantation. ${ }^{3}$ This combined with an ageing population would suggest that the problem may already have run its course. However, a more recent review emphasised that the problem remains prevalent, ${ }^{4}$ suggesting that lens opacification may be an under recognised complication of cataract surgery and thus there is potentially an unmet need.

Many studies investigating IOL opacification have listed glare and mistiness among the most common presenting complaints; ${ }^{4,18,22}$ however, no studies to date have assessed the extent of glare in patients with opacified IOLs. The aim of this study was to quantify the effect of delayed postoperative Hydroview optic opacification on glare, and relate our observations to other aspects of visual function and quality of life.

\section{Materials and methods}

The authors certify that all applicable institutional and governmental regulations concerning the ethical use of human volunteers were followed during this research. This study was granted approval by the Central and South Bristol Research Ethics Committee (ref 05/Q2006/ 163). Informed consent was obtained from all participants.

\section{Population}

All patients who underwent cataract surgery with Hydroview lens implantation at the Bristol Eye Hospital (BEH) between the 1st December 2000 and the 28th February 2001 were invited to take part in the study. These census dates were chosen on evidence from a local audit showing that the majority of patients presenting with opacified Hydroview lenses had undergone surgery between these dates. In addition, any patients presenting to $\mathrm{BEH}$ with opacified Hydroview lenses implanted outside this period were also invited to be included. All patients had a Hydroview IOL implanted in their study eye, which may be clear or have evidence of opacification, and a clear lens in their non-study eye. Any patients with ocular co-morbidity in either eye that would affect vision, identified through history or examination such as posterior capsular opacity, glaucoma, and macular pathology, were excluded.

\section{Outcome measures}

The primary outcome was the effect of glare on vision, measured as intraocular straylight using the C-Quant instrument (Oculus GmBH, Wetzlar, Germany). This uses a compensation-comparison method to measure forward light scatter, which has been described in detail elsewhere. ${ }^{23}$ Briefly, the C-Quant tests each eye individually by presenting two semicircles centrally, surrounded by a ring-shaped light source, which is flickering on and off. The subject is advised to look directly at the two semicircles. Some of the light from the flickering source is reflected back from the eye (through forward light scatter) onto the central semicircles making them appear to flicker. One of the semicircles is illuminated by a light flickering in counter-phase to the ring light source, compensating for it, whereas the other is only illuminated by forward light scatter from the subject's eye. The subject is instructed to compare the two semicircles and to indicate which is flickering the most by pressing one of two buttons. In this way the subject is comparing different compensation values to no compensation. The method uses two indices of reliability, Esd (expected standard deviation) must be $\leqslant 0.08$ and $\mathrm{Q}$ must be $\geqslant 1.0$. Measurements with reliability falling outside of these criteria were not included in the analysis. This has been shown to be a reliable and valid method of measuring intraocular straylight. ${ }^{24,25}$ The Commission International de l'Eclairage quantifies disability glare as straylight. $^{26}$

The following secondary outcome measures were investigated. Vision related quality of life as measured by the Vision Core Module 1 (VCM-1) questionnaire. This is a 10-item questionnaire, which addresses the degree to which a subject's visual impairment leads to feelings of embarrassment, frustration, isolation, or concern about their ability to cope. Each item is scored $0-5$ giving a total score out of 50, higher scores reflecting a lower visionrelated quality of life. Full details of the development and validity of this questionnaire have been published elsewhere. ${ }^{27,28}$ Subjective visual symptoms of blur, misty vision, glare, and loss of colour vision were also assessed by questionnaire for each eye.

In addition to the measurement of glare by intraocular straylight, a range of objective tests of visual function were performed. Disability glare was also measured by the Optec 6500 (Stereo Optical Co., Inc., Chicago, IL, USA) using the functional acuity contrast testing charts in photopic conditions. The number of targets correctly identified with and without a glare source was measured. Other objective visual tests included visual acuity (logarithm of the minimum angle of resolution, $\log$ MAR scale) as measured on a modified Early Treatment of Diabetic Retinopathy Study chart with Sloan letters, contrast sensitivity was assessed with a Pelli-Robson chart, colour vision was assessed with Ishihara charts, and visual field as measured using frequency doubling technology (FDT) perimetry (24-2 threshold test). 
All subjects underwent a dilated examination on a slit lamp bio-microscope by the same ophthalmologist. Lenses were graded as to whether or not they had the presence or absence of opacification. The appearance of the lenses was documented with anterior segment and Scheimpflug photography (Pentacam, Oculus GmBH).

Surgical details and co-morbidity were elicited from review of notes and examination of subjects.

\section{Statistical methods}

Statistical analysis was first performed by comparing results from the study eye of subjects with an opacified lens (opacified group) with the study eye of subjects with a clear lens (clear group). Means of normally distributed data (namely straylight, logMAR and disability glare) were compared with Student's $t$-tests. Non-parametric Mann-Whitney $U$-tests were used for the remainder.

Given that differences in vision could occur between the groups because of some unknown factor unrelated to opacification, that would equally affect the study and non-study eyes, further parametric comparisons were performed incorporating covariate adjustments for the measurements in the non-study eye.
Finally, as a further validation for the opacified group only, paired comparisons were made between the study eye and non-study eye for each group, using paired Student's $t$-tests or Wilcoxon matched-pairs signed ranks tests as appropriate.

A $5 \%$ level of significance was used throughout.

\section{Results}

Between December 2000 and February 2001, 915 patients had Hydroview IOLs implanted over this period at the $\mathrm{BEH}$, one of which was bilateral.

Of these, 327 had died, 55 did not meet the inclusion criteria based on data contained in their notes and 55 were unable to be contacted (see Figure 1). A total of 478 patients were contacted to offer inclusion onto the study, 269 declined, and 209 were recruited. Of the 209 remaining, 84 patients failed to meet inclusion criteria on examination.

Six further patients were considered whose lenses were implanted outside of the dates set for the recall, but presented to BEH with opaque Hydroview lenses. Four of these six met inclusion criteria on examination (ie they

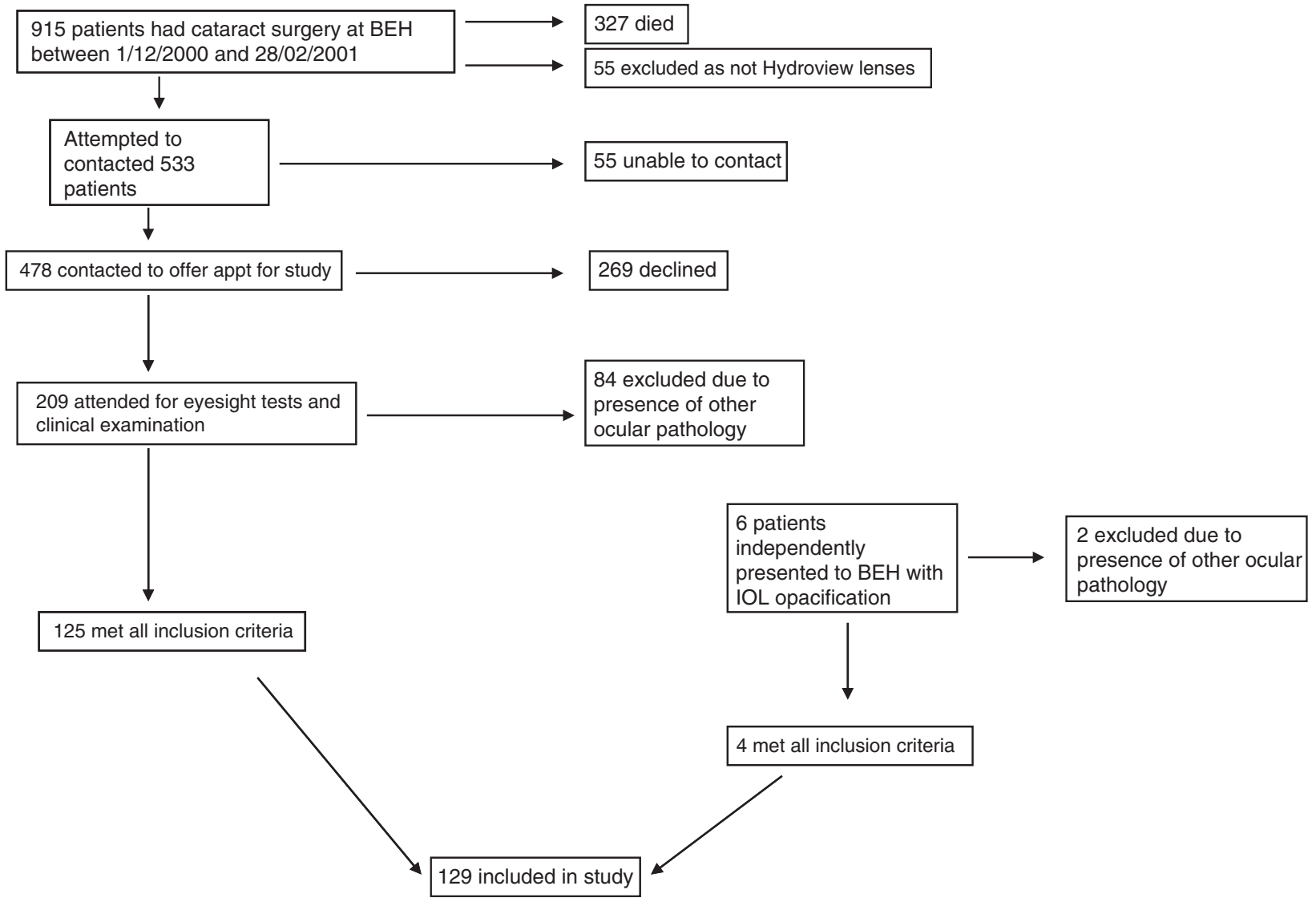

Figure 1 Flow chart of patient inclusion onto the study as per consort guidelines. 
had no other ocular pathology affecting vision) and were included in the analyses.

In total, data from 129 patients were analysed, none of whom had bilateral opacified Hydroview implanted lenses. Fifty subjects had opacified IOLs in their study eye compared with 79 with clear IOLs in their study eye. No subject had bilaterally opacified IOLs. Mean age was 79 years (range 20-96) and mean time from IOL implantation to assessment was 7.04 years (range 6.43-7.49). There were no statistically significant differences in age or time from implantation to assessment between the two groups.

\section{Symptoms}

Subjects with opacified IOLs had a greater frequency of visual symptoms as shown in Table 1. Symptoms which the opacified lens group rated as more severe and which achieved statistical significance included blurred vision, misty vision, being dazzled by bright lights, seeing star shapes around lights, seeing haloes around lights, and colours seeming dull. Subjects with opacified IOLs described their overall eyesight as worse than those with clear IOLs.

\section{Objective measures of visual function}

The results of the objective measures of visual function carried out are summarised in Table 2.

Of the 129 subjects included, 62 were able to perform the test for straylight (C-Quant) well enough to provide an accurate value for straylight; the reliability values for the remainder were too poor for their inclusion (Esd $\geqslant 0.08$ or $Q \leqslant 1.0$ ). Subjects with opacified IOLs showed increased glare measured as straylight, mean $=1.94 \log$ units (SD, $0.30 ; n=17)$, compared with subjects with clear IOLs, mean $=1.35$ (SD, $0.35 ; n=45)$. The covariate adjusted mean difference was $0.63 \mathrm{log}$ units (95\% CI, 0.45-0.82; $P<0.001$ ) (see Figure 2). This represents a level of glare on average four times worse among the opacified group.

All subjects were able to perform the glare test on the Optec 6500. Measurement of glare by the Optec 6500 also showed a large difference between the opacified and clear groups. Subjects with opacified IOLs showed increased glare, mean $=5.3(\mathrm{SD}, 6.3: n=50)$, compared with subjects with clear IOLs, mean $=0.8(\mathrm{SD}, 5.2$; $n=79)$. The adjusted mean difference was 4.5 (95\% CI, 2.6-6.3; $P<0.001)$. This represents a level of disability glare six times worse among the opacified group.

Contrast sensitivity among the group with clear study eye lenses was 1.65 (range $0-1.95, n=79$ ), whereas the opacified IOL group averaged a score of 1.05 (range $0-1.65, n=49)$, resulting in a median difference of
Table 1 Results of subjective assessment of visual function

Study eye

Median score on

questionnaire $0-5$

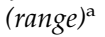
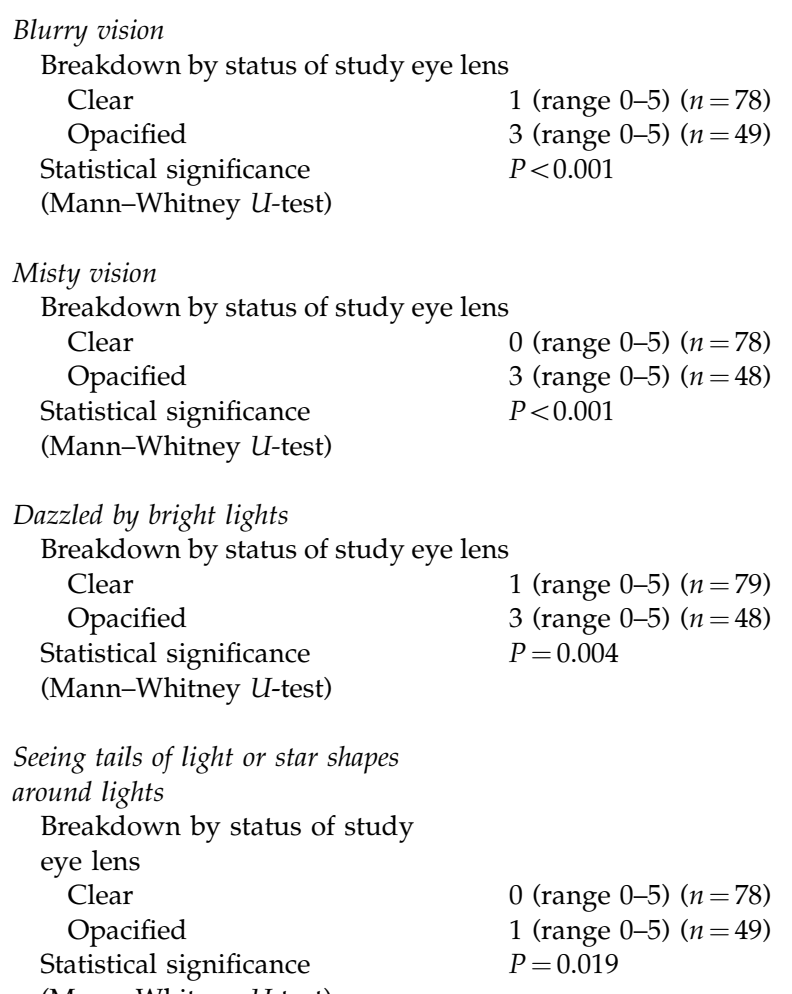

(Mann-Whitney $U$-test)

Seeing haloes or rings around lights

Breakdown by status of study

eye lens

Clear

Opacified

Statistical significance

(Mann-Whitney $U$-test)

0 (range $0-5)(n=79)$

1 (range $0-5)(n=49)$

$P=0.009$

Colours seem dull or faded

Breakdown by status of study eye lens Clear

Opacified

0 (range $0-5)(n=79)$

2 (range $0-5)(n=48)$

Statistical significance

(Mann-Whitney $U$-test)

$P<0.001$

Describe the eyesight overall

Breakdown by status of study eye lens Clear

Opacified

Statistical significance

(Mann-Whitney U-test)

Comparisons were made between subjects with clear lens in their study eye and those with an opacified lens (shown vertically, within columns). ${ }^{\mathrm{a}} 0=$ does not experience the symptom; $5=$ worst experience of the symptom. 
Table 2 Results of objective tests of visual function

\begin{tabular}{|c|c|c|c|}
\hline & $\begin{array}{l}\text { Study eye mean (SD) } \\
\text { (or median (range) where } \\
\text { indicated with an asterisk) }\end{array}$ & $\begin{array}{l}\text { Non-study eye mean }(S D) \\
\text { (or median (range) where } \\
\text { indicated with an asterisk) }\end{array}$ & $\begin{array}{l}\text { Paired comparison between } \\
\text { study and non-study eye } \\
\text { (opacified lenses only) }\end{array}$ \\
\hline \multicolumn{4}{|c|}{ Glare (measured as straylight using a C-Quant) } \\
\hline \multicolumn{4}{|c|}{$\begin{array}{l}\text { Breakdown by status of } \\
\text { study eye lens }\end{array}$} \\
\hline Clear & $1.35(\mathrm{SD}, 0.35)(n=45)$ & $1.20(\mathrm{SD}, 0.23)(n=47)$ & \\
\hline Opacified & $1.94(\mathrm{SD}, 0.30)(n=17)$ & $1.31(\mathrm{SD}, 0.16)(n=31)$ & $\begin{array}{l}\text { Mean difference } 0.78 \\
(95 \% \mathrm{CI}, 0.60-0.96) \\
P<0.001\end{array}$ \\
\hline Mean difference & $\begin{array}{l}0.60(95 \% \text { CI, } 0.40-0.79) \\
P<0.001\end{array}$ & $\begin{array}{l}0.11(95 \% \text { CI, } 0.02-0.21) \\
P=0.022\end{array}$ & \\
\hline Adjusted $^{a}$ mean difference & $\begin{array}{l}0.63(95 \% \text { CI, } 0.45-0.82) \\
P<0.001\end{array}$ & & \\
\hline \multicolumn{4}{|c|}{$\begin{array}{l}\text { Breakdown by status of } \\
\text { study eye lens }\end{array}$} \\
\hline Clear & $0.8(\mathrm{SD}, 5.2)(n=79)$ & $1.0(\mathrm{SD}, 3.6)(n=79)$ & \\
\hline Opacified & $5.3(\mathrm{SD}, 6.3)(n=50)$ & $1.0(\mathrm{SD}, 3.9)(n=50)$ & $\begin{array}{l}\text { Mean difference } 4.3 \\
(95 \% \mathrm{CI}, 1.7-6.9) \\
P=0.002\end{array}$ \\
\hline Mean difference & $\begin{array}{l}4.4(95 \% \text { CI, 2.4-6.5) } \\
P<0.001\end{array}$ & $\begin{array}{l}0.0(95 \% \mathrm{CI},-1.3 \text { to } 1.3) \\
P=0.98\end{array}$ & \\
\hline Adjusted $^{a}$ mean difference & $\begin{array}{l}4.5(95 \% \text { CI, 2.6-6.3) } \\
P<0.001\end{array}$ & & \\
\hline \multicolumn{4}{|c|}{$\begin{array}{l}\text { Breakdown by status of } \\
\text { study eve lens }\end{array}$} \\
\hline Clear & $1.65^{\mathrm{b}}($ range $0-1.95)(n=79)$ & 1.50 (range $0-1.95)(n=79)$ & \\
\hline Opacified & 1.05 (range $0-1.65)(n=49)$ & $1.50($ range $0.15-1.95)(n=49)$ & $\begin{array}{l}\text { Wilcoxon matched-pairs } \\
\text { signed ranks tests; } \\
P<0.001 \text { on } n=49 \text { pairs }\end{array}$ \\
\hline Median difference & $\begin{array}{l}-0.45(95 \% \mathrm{CI},-0.3 \text { to }-0.6) \\
P<0.001\end{array}$ & $\begin{array}{l}0(95 \% \mathrm{CI},-0.2 \text { to } 0) \\
P=0.14\end{array}$ & \\
\hline \multicolumn{4}{|c|}{$\begin{array}{l}\text { Breakdown by status of } \\
\text { study eye lens }\end{array}$} \\
\hline Clear & $1^{\mathrm{b}}($ range $0-49)(n=77)$ & 0 (range $0-42)(n=77)$ & \\
\hline Opacified & 19 (range $0-51)(n=49)$ & 0 (range $0-51)(n=49)$ & $P<0.001$ on $n=49$ pairs \\
\hline Median difference & 10 (95\% CI, 5-23) $P<0.001$ & $\begin{array}{l}0 \text { (95\% CI, }-0.001 \text { to } 0.001) \\
P=0.62\end{array}$ & \\
\hline \multicolumn{4}{|c|}{$\begin{array}{l}\text { Visual acuity (measured as logMAR using a modified ETDRS chart) } \\
\text { Breakdown by status of } \\
\text { study eye lens }\end{array}$} \\
\hline Clear & $0.157(\mathrm{SD}, 0.147)(n=79)$ & $0.134(\mathrm{SD}, 0.148)(n=79)$ & \\
\hline Opacified & $0.275(\mathrm{SD}, 0.257)(n=49)$ & $0.171(\mathrm{SD}, 0.196)(n=49)$ & $\begin{array}{l}\text { Mean difference } 0.10 \\
(95 \% \mathrm{CI}, 0.04-0.17) \\
P=0.003\end{array}$ \\
\hline Mean difference & $\begin{array}{l}0.12(95 \% \text { CI, } 0.05-0.19) \\
P=0.001\end{array}$ & $\begin{array}{l}0.04(95 \% \mathrm{CI},-0.02 \text { to } 0.10) \\
P=0.23\end{array}$ & \\
\hline Adjusted $^{\mathrm{a}}$ mean difference & $\begin{array}{l}0.09(95 \% \text { CI, } 0.03-0.15) \\
P=0.002\end{array}$ & & \\
\hline \multicolumn{4}{|c|}{$\begin{array}{l}\text { Colour vision (as measured using an Ishihara chart) } \\
\text { Breakdown by status of } \\
\text { study eye lens }\end{array}$} \\
\hline Clear & $\begin{array}{l}\left.20^{\mathrm{b}} \text { (mean } 18.0 ; \text { range } 1-21\right) \\
(n=77)\end{array}$ & $\begin{array}{l}20 \text { (mean } 18.3 ; \text { range } 3-21) \\
(n=76)\end{array}$ & \\
\hline
\end{tabular}


Table 2 (Continued)

\begin{tabular}{llll}
\hline & $\begin{array}{l}\text { Study eye mean }(S D) \\
\text { (or median (range) where } \\
\text { indicated with an asterisk) }\end{array}$ & $\begin{array}{l}\text { Non-study eye mean }(S D) \\
\text { (or median (range) where } \\
\text { indicated with an asterisk) }\end{array}$ & $\begin{array}{l}\text { Paired comparison between } \\
\text { study and non-study eye } \\
\text { (opacified lenses only) }\end{array}$ \\
\hline Opacified & $\begin{array}{l}19 \text { (mean 17.4; range } 1-21) \\
(n=47)\end{array}$ & $\begin{array}{l}20 \text { (mean 18.7; range 3-21) } \\
(n=49)\end{array}$ & $\begin{array}{l}P<0.001 \text { on } \\
n=47 \text { pairs }\end{array}$ \\
Median difference & $0(95 \% \mathrm{CI},-1$ to 0$) P=0.48$ & $0(95 \% \mathrm{CI}, 0-1) P=0.43$ &
\end{tabular}

Comparisons were made between subjects with clear lens in their study eye and those with an opacified lens (shown vertically, within columns). Comparisons were also made between the subjects' non-study eyes. To account for any difference between subjects' vision that was not a result of opacification of the IOL, where possible a covariate adjustment was made for the corresponding result in the non-study eye. The study eyes of those with opacified lenses were further compared with their respective non-study eyes (shown horizontally, within rows).

${ }^{a}$ Adjusts for the result in non-study eye as a covariate.

${ }^{\mathrm{b}}$ Median (range); note $95 \%$ CIs for median differences only approximate.

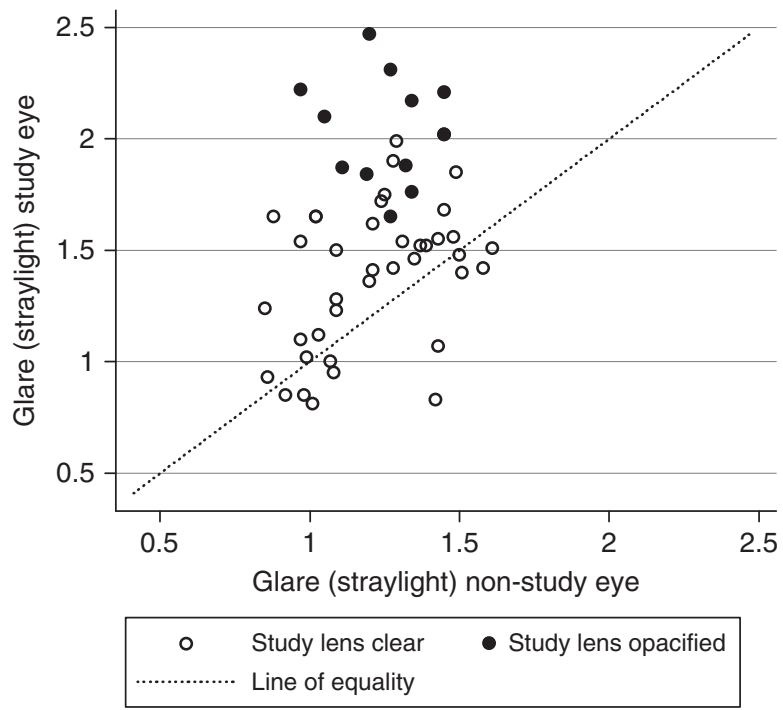

Figure 2 Scatter graph comparing glare (measured as intraocular straylight) between study eyes (with either clear lenses (circles) or opacified lenses (black dots)) and their respective non-study eyes. The dotted line is the 'line of equality', signifying no difference in glare between study eye and non-study eye.

0.45 (95\% CI, 0.3-0.6; $P<0.001 ;$ Mann-Whitney $U$-test) the equivalent of three triplets or one and a half lines.

Visual field as measured by FDT showed a marked difference between the groups with average scores of 1 (range $0-49, n=77$ ) and 19 (range $0-51, n=49$ ) for the opacified group and the clear group, respectively.

Visual acuity measured in logMAR units did show a statistically significant adjusted mean difference between the two groups, but only of $0.09 \log$ MAR units $(95 \% \mathrm{CI}$, $0.03-0.15 ; P=0.002$ ) (see Figure 3 ). This equates to only four and a half letters difference, less than one line.

There was no statistically significant association between opacification and colour vision measured by Ishihara chart $(P=0.476$, Mann-Whitney $U$-test).

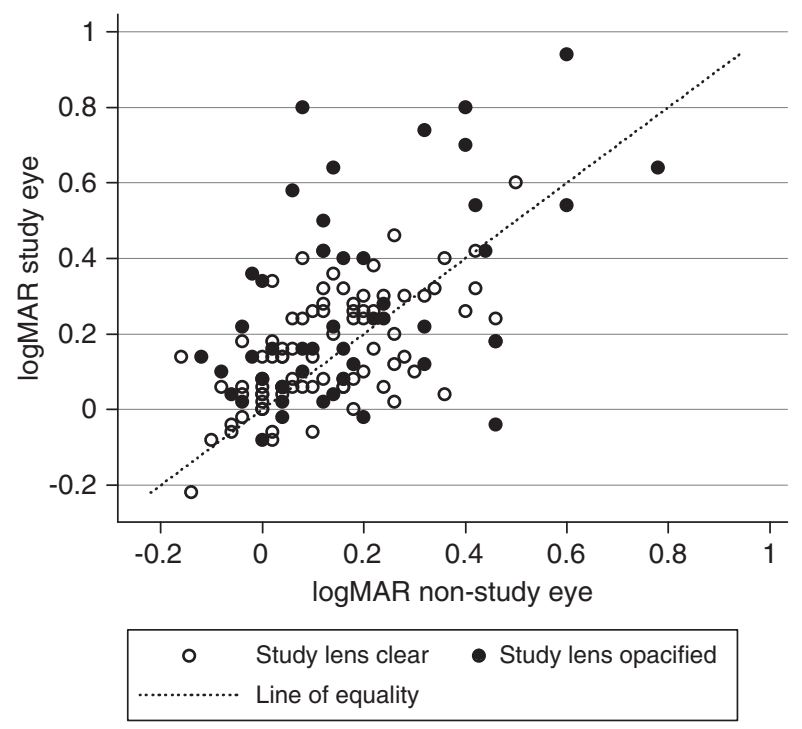

Figure 3 Scatter graph comparing visual acuity (measured in $\operatorname{logMAR}$ units) between study eyes (with either clear lenses (circles) or opacified lenses (black dots)) and their respective non-study eyes. The dotted line is the 'line of equality', signifying no difference in visual acuity between study and non-study eyes.

As can be seen in Table 2, similar results were obtained using paired comparisons between the study eye and non-study eye of the opacified group.

Although we could get $\log$ MAR acuity measurements for virtually all the subjects, only a proportion was able to perform a straylight measurement accurately enough to be included in analysis. An important factor was that many subjects with severe opacification could not perform the test accurately because of the high levels of straylight generating values outside detection levels for the apparatus. The result of this is that the groups compared in terms of straylight differ from those compared in terms of acuity as we have effectively excluded the most severely affected from the straylight 
analysis, but not from the acuity analysis. By including data only from subjects who could perform the straylight test in analysis for acuity, we see a more accurate comparison, albeit by excluding those most severely affected from each group. By analysing the data in this way, we see no statistically or clinically significant difference in terms of acuity between the opacified group (mean logMAR 0.121, approximately equivalent to 20/25 Snellen) and the clear group (mean logMAR 0.125, approximately equivalent to $20 / 25$ Snellen). Using these data, the acuity is represented by a mean difference of 0.004 between the opacified and clear groups, less than one letter difference, which contrasts with the dramatic difference between groups in terms of straylight of 0.63 $\log$ units.

\section{Quality of life}

Opacification was associated with increased VCM1 scores, indicating a lower visual-related quality of life; the median scores for clear lenses and opacified lenses, respectively, were 2.5 (range $0-34$ ) and 8.5 (range $0-35$ ) out of $50(P<0.001$, Mann-Whitney $U$-test $)$.

\section{Discussion}

This large cross-sectional study of Hydroview opacification is the first to have assessed formally glare in vivo. The finding that Hydroview opacification has a dramatically greater effect on glare than on visual acuity is, therefore, original and of great interest, particularly in the assessment of patients for IOL exchange.

A possible explanation of why this is the case was put forward by van der Meulen $e t a l^{8}$ in a paper examining opaque Aquasense lenses in vitro. The authors postulated that the small deposits, of a size approximating the wavelength of light, within these affected lenses would be sufficient to cause increased straylight, whereas it requires larger irregularities $(>100 \mu \mathrm{m})$ to affect acuity. The same theory has been put forward regarding straylight produced by opacities in the natural lens. ${ }^{29}$ An earlier study investigating Hydroview lenses specifically showed that individual deposits in explanted opacified lenses vary in size from $<1$ to $3-7 \mu$ m before they seem to coalesce to form larger deposits. ${ }^{6}$ The authors' proposal that the deposits in Hydroview lenses begin as small subsurface particles before breaking the surface and coalescing to form larger deposits would explain the relative lack of loss of acuity compared with glare that we have found, especially among subjects with lenses less severely affected.

It is interesting to note that, in the analysis of straylight data, the study eye lenses had higher values of straylight than the non-study eyes even within the clear lens group.
It is possible that even clear Hydroview IOLs create more straylight. In the analysis, we have compensated for this in case it is from some influence affecting vision other than the IOL that has not been accounted for. It is unlikely that this phenomenon is caused by operator or subject bias as the test is very resistant to fraud from the subject and, because of the nature of the test, it is almost impossible for the operator to influence the subject's result. It is possible that the difference could be caused by other ocular pathology affecting the vision that was unnoticed, although this is unlikely as the patients all had their medical records reviewed and underwent dilated slit lamp examination immediately after the tests of vision. To allow missed pathology to influence the results in this way, it would have to be predominantly missed in the study eyes rather than the non-study eyes, which seems unlikely. An alternate explanation of the higher study eye value is that these subjects have some degree of opacification in their study eye lens, but that the deposits were too small to be visible on slit lamp bio-microscopy. However, as the only way to prove this would be through in vitro analysis of the lens, requiring a subject to undergo lens exchange surgery on an apparently clear lens, we are unlikely to be able to test the hypothesis.

Our work correlates well with earlier work by van Bree et $a l^{26}$ and van den Berg et $a l^{29}$ which shows that glare, measured as straylight, is independent of acuity and contrast sensitivity. Our results suggest that the level of glare is on average four times worse among the opacified group than the group with clear lenses. This would be equivalent to a loss of approximately six lines of Snellen visual acuity if compared. ${ }^{26}$ In addition to increased glare, our study also showed a significant decrease in contrast sensitivity correlating well with the work by Altaie et al..$^{5}$ This could explain the anecdotal experience of patients having good acuity yet requesting surgery and of patients whose acuity did not improve greatly post-surgery, but were very pleased with the result. Although changes in acuity did not correlate with the patient's experience, changes in contrast sensitivity and visual disability caused by glare may well have.

Our study has a number of limitations. It was only possible to collect data fit for analysis on $14 \%$ of total cohort (129 of 916). Selection bias may have been introduced, because it could be argued that subjects with an opacified IOL might either be more likely than asymptomatic patients to participate because of the symptoms caused by their IOL or more reluctant to participate because of a loss of trust in the hospital. For these reasons, our sample cannot be considered directly representative of total cohort. However, as our sample includes opacified and clear Hydroview IOLs, it is reasonable to make statements regarding the impact of 
this opacification on visual performance and experience. For this reason, it was considered acceptable to include patients with opacified IOLs that presented outside of the recall dates to increase the dataset for the opacified group.

The important implication of these findings is that glare and contrast sensitivity should be measured to assess the impact of IOL opacification on visual performance and experience. Indeed, glare and contrast sensitivity measures should be incorporated into the decision-making process in which exchange of opacified IOLs is under consideration. Our group is in the process of taking this work further by investigating how vision is affected by lens exchange surgery.

\section{Summary}

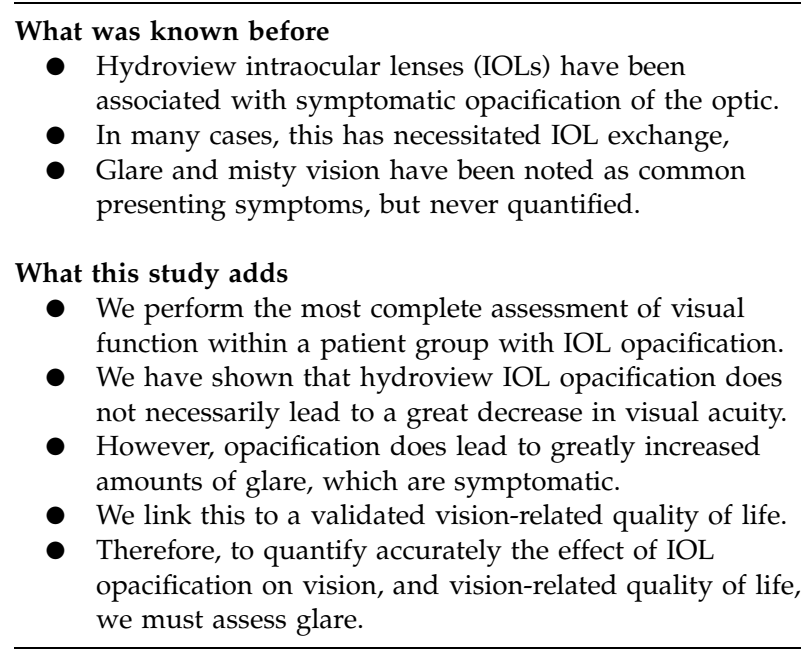

\section{Conflict of interest}

The authors declare no conflict of interest.

\section{Acknowledgements}

Bausch and Lomb kindly gave financial support to this study to cover patient care. Stereo Optical kindly donated the OPTEC 6500 for use in this study.

\section{References}

1 Hospital Episode Statistics for England: Headline Figures. The Information Centre for Health and Social Care. [cited; Available from:http://www.hesonline.nhs.uk/Ease/servlet/ AttachmentRetriever?site_id $=1937 \&$ file_name $=$ d: $\backslash$ efmfiles $\backslash$ 1937\Accessing \DataTables \Headline $\backslash$ Headline_0708.pdf \&short_name $=$ Headline_0708.pdf\&u_id $=8220$.

2 Cleary G, Spalton DJ, Koch DD. Effect of square-edged intraocular lenses on neodymium:YAG laser capsulotomy rates in the United States. J Cataract Refract Surg 2007; 33(11): 1899-1906.
3 MHRA report MDA/2004/015 - Bausch \& Lomb HYDROVIEW H60M Intraocular Lens. Medicines and Healthcare Products Regulatory Agency 2004.

4 Syam P, Syam P, Byrne P, Lewis G, Husain T, Kleinmann G et al. Hydroview lens implant calcification: 186 exchanges at a district general hospital. Eye 2006; 22(3): 325-331.

5 Altaie RW, Costigan T, Donegan S, O'brien P, Mahmood U, Bogdan $\mathrm{AJ}$ et al. Investigation and management of an epidemic of Hydroview intraocular lens opacification. Graefes Arch Clin Exp Ophthalmol 2005; 243(11): 1124-1133.

6 Knox Cartwright NE, Mayer EJ, McDonald BM, Skinner A, Salter CJ, Tole DM et al. Ultrastructural evaluation of explanted opacified Hydroview (H60M) intraocular lenses. Br J Ophthalmol 2007; 91(2): 243-247.

7 Neuhann IM, Kleinmann G, Apple DJ. A new classification of calcification of intraocular lenses. Ophthalmology 2008; 115(1): 73-79.

8 van der Meulen IJ, Porooshani H, van den Berg TJ. Lightscattering characteristics of explanted opacified Aquasense intraocular lenses. Br J Ophthalmol 2009; 93(6): 830-832.

9 Neuhann IM, Werner L, Izak AM, Pandey SK, Kleinmann G, Mamalis $\mathrm{N}$ et al. Late postoperative opacification of a hydrophilic acrylic (hydrogel) intraocular lens: a clinicopathological analysis of 106 explants. Ophthalmology 2004; 111(11): 2094-2101.

10 Tehrani M, Mamalis N, Wallin T, Dick HB, Stoffelns BM, Olson $\mathrm{R}$ et al. Late postoperative opacification of MemoryLens hydrophilic acrylic intraocular lenses: case series and review. J Cataract Refract Surg 2004; 30(1): 115-122.

11 Mattova J, Bohácová E, Murgasová Z, Kadlec R, Forgác F, Klobusická E et al. Opacification of hydrophilic MemoryLens U940A intraocular lenses: analysis of 2 explanted lenses. J Cataract Refract Surg 2004; 30(9): 1934-1939.

12 Izak AM, Werner L, Pandey SK, Apple DJ. Calcification of modern foldable hydrogel intraocular lens designs. Eye 2003; 17(3): 393-406.

13 Apple DJ, Werner L. Complications of cataract and refractive surgery: a clinicopathological documentation. Trans Am Ophthalmol Soc 2001; 99: 95-107; discussion 107-109.

14 Saeed MU, Jafree AJ, de Cock R. Intralenticular opacification of hydrophilic acrylic intraocular lenses. Eye 2005; 19(6): 661-664.

15 Werner L, Apple DJ, Kaskaloglu M, Pandey SK. Dense opacification of the optical component of a hydrophilic acrylic intraocular lens: a clinicopathological analysis of 9 explanted lenses. J Cataract Refract Surg 2001; 27(9): 1485-1492.

16 Werner L, Hunter B, Stevens S, Chew JJ, Mamalis N. Role of silicon contamination on calcification of hydrophilic acrylic intraocular lenses. Am J Ophthalmol 2006; 141(1): 35-43.

17 Izak AM, Werner L, Pandey SK, Macky TA, Trivedi RH, Apple DJ. Calcification on the surface of the Bausch \& Lomb Hydroview intraocular lens. Int Ophthalmol Clin 2001; 41(3): 63-77.

18 Habib NE, Freegard TJ, Gock G, Newman PL, Moate RM. Late surface opacification of Hydroview intraocular lenses. Eye 2002; 16(1): 69-74.

19 Fernando GT, Crayford BB. Visually significant calcification of hydrogel intraocular lenses necessitating explantation. Clin Experiment Ophthalmol 2000; 28(4): 280-286.

20 Werner L, Apple DJ, Escobar-Gomez M, Ohrström A, Crayford BB, Bianchi $\mathrm{R}$ et al. Postoperative deposition of 
calcium on the surfaces of a hydrogel intraocular lens. Ophthalmology 2000; 107(12): 2179-2185.

21 Sher JH, Gooi P, Dubinski W, Brownstein S, El-Defrawy S, Nash WA. Comparison of the incidence of opacification of Hydroview hydrogel intraocular lenses with the ophthalmic viscosurgical device used during surgery. J Cataract Refract Surg 2008; 34(3): 459-464.

22 Dorey MW, Brownstein S, Hill VE, Mathew B, Botton G, Kertes PJ et al. Proposed pathogenesis for the delayed postoperative opacification of the hydroview hydrogel intraocular lens. Am J Ophthalmol 2003; 135(5): 591-598.

23 Franssen L, Coppens JE, van den Berg TJ. Compensation comparison method for assessment of retinal straylight. Invest Ophthalmol Vis Sci 2006; 47(2): 768-776.

24 Coppens JE, Franssen L, van Rijn LJ, van den Berg TJ. Reliability of the compensation comparison stray-light measurement method. J Biomed Opt 2006; 11(3): 34027.

25 van Rijn LJ, Nischler C, Gamer D, Franssen L, de Wit G, Kaper $\mathrm{R}$ et al. Measurement of stray light and glare: comparison of Nyktotest, Mesotest, stray light meter, and computer implemented stray light meter. $\mathrm{Br} J$ Ophthalmol 2005; 89(3): 345-351.

26 van Bree MC, Zijlmans BL, van den Berg TJ. Effect of neodymium:YAG laser capsulotomy on retinal straylight values in patients with posterior capsule opacification. J Cataract Refract Surg 2008; 34(10): 1681-1686.

27 Frost NA, Sparrow JM, Durant JS, Donovan JL, Peters TJ, Brookes ST. Development of a questionnaire for measurement of vision-related quality of life. Ophthalmic Epidemiol 1998; 5(4): 185-210.

28 Frost NA, Sparrow JM, Hopper CD, Peters TJ. Reliability of the VCM1 questionnaire when administered by post and by telephone. Ophthalmic Epidemiol 2001; 8(1): 1-11.

29 van den Berg TJ, van Rijn LJ, Michael R, Heine C, Coeckelbergh T, Nischler C et al. Straylight effects with aging and lens extraction. Am J Ophthalmol 2007; 144(3): 358-363. 